Industry and Innovation

\title{
Product innovation success based on cancer research in the pharmaceutical industry: co- publication networks and the effects of partners
}

\section{Maureen McKelvey \& Bastian Rake}

To cite this article: Maureen McKelvey \& Bastian Rake (2016) Product innovation success based on cancer research in the pharmaceutical industry: co-publication networks and the effects of partners, Industry and Innovation, 23:5, 383-406, DOI: 10.1080/13662716.2016.1150157

To link to this article: https://doi.org/10.1080/13662716.2016.1150157

曲 Published online: 09 Mar 2016.

Submit your article to this journal $\pi$

III Article views: 283

Q View related articles 5

View Crossmark data $־$

Citing articles: 6 View citing articles ๔ 


\title{
Product innovation success based on cancer research in the pharmaceutical industry: co-publication networks and the effects of partners
}

\author{
Maureen McKelvey ${ }^{\mathrm{a}}$ (D) and Bastian Rake ${ }^{\mathrm{b}}$ (iD \\ aDepartment of Economy and Society, Institute of Innovation and Entrepreneurship, Gothenburg, Sweden; \\ ${ }^{b}$ Chair for Organisation, Technology Management and Entrepreneurship, University of Passau, Passau, \\ Germany
}

\begin{abstract}
This paper builds upon the literature which provides conflicting theoretical insights and empirical results concerning the importance of companies' collaborative relations, their position within a network of collaborative relations and the effects on their innovative performance. Taking the importance of collaborations and networks in the pharmaceutical industry into account, the paper untangles the influence of the firm's co-publication relations with different types of partners and its network position on the company's product innovation in a specific disease area-cancer. We find rather robust evidence that in particular, companies' indirect connections within the co-publication network, including connections to academic institutions and biotechnology companies, support product innovation. In contrast to evidence in the strategic alliance literature, direct co-publication links to biotechnology companies do not support product innovation in terms of new cancer medications.
\end{abstract}

\section{KEYWORDS}

Research networks; research collaboration; product innovation; innovative performance; pharmaceuticals

JEL

L25; L65; 031

\section{Introduction}

In an increasingly complex scientific and technological environment, firms do not conduct their innovative activities in isolation, but are embedded in their surroundings. Literature argues that the locus of innovation is no longer the individual actor, but the entire network (Powell and Brantley 1992; Powell and Grodal 2005; Powell, Koput, and Smith-Doerr 1996). Moreover, a stream of literature suggests that a firm's position within a research network influences its innovative output, particularly in industries in which the knowledge base is rapidly developing, complex and widely dispersed (Owen-Smith et al. 2002; Powell et al. 1999). The reason is that in these industries, no organization can simultaneously be up to date with the progress in all knowledge areas necessary for successful innovative activities (Nooteboom 1999, 2009). Hence, collaboration through networks is a means to pool, exchange and develop new knowledge. Under these conditions, the structure of the entire 
network as well as the actors' position within it determine their access to the relevant knowledge sources. Therefore, the network will affect actors' innovative activities and performance (Kogut, Shan, and Walker 1992). In the case of biotechnology and pharmaceuticals, the development of new products strongly relies upon novel ideas, particularly those generated through medical and biological scientific research. However, at the same time, the capabilities of the firm in acting in this complex network and fast-paced environment must be investigated as well. Our paper contributes to the literature, by untangling the influence of the firm's collaborative relations with different partner types and their network position, within the specific area of biotechnology and pharmaceutical industry.

In their literature review, Phelps, Heidl, and Wadhwa (2012) point out that research addressing the relationship between companies' collaborative relations and their position within networks has led to conflicting results concerning the influence of these factors on innovative performance. The authors conclude that the number of collaboration partners per se does not sufficiently account for the diversity of collaborative relations, knowledge generation and exchange. In this paper, we are interested in networks in the context of the firm, and its innovative performance. Networks may be useful because the recombination of existing knowledge is as an important source of novelty and innovation (Nelson and Winter 1982; Schumpeter 1939). Hence, conceptually, companies can use collaboration in networks as a complementary activity to their internal capabilities for knowledge and innovation.

The pharmaceutical and biotechnology industry is a particularly interesting and important context to try to further untangle the relationships between partners for scientific publications, networks and innovative performance of the firm. Recent research has demonstrated the increasing importance of networks and collaboration partners in promoting new products in this industry (Rafols et al. 2014). The pharmaceutical industry is characterized by tremendous growth in $\mathrm{R} \& \mathrm{D}$ and in collaboration for development and marketing among different types of actors (Powell et al. 2005; Roijakkers and Hagedoorn 2006). Within the pharmaceutical sector, networks are created by interactions between heterogeneous actors, who are linked through a web of different types of relations involving knowledge, markets, regulations and so forth (McKelvey, Orsenigo, et al. 2004). Thus, research for pharmaceutical product innovations is increasingly conducted in collaboration with a broad range of different partners, and innovations rely upon numerous actors, who are involved at different stages from drug discovery to drug testing and approval.

Within this industry, this paper focuses upon knowledge and innovation for one specific disease area, namely cancer. Few-if any-existing studies have examined cancer pharmaceutical research in terms of the global nature of networks across multiple types of actors and the impact on product innovation. Cancer research is a vital area for both public and private investment into health care, and represents a treatment area with an expanding market for pharmaceuticals. Cancer is one of the leading causes of death worldwide, with approximately 8.2 million individuals succumbing to cancer every year and more than 14 million new cases diagnosed annually. According to the International Agency for Research on Cancer (International Agency for Research on Cancer 2014) both numbers are expected to rise considerably in the course of the next two decades. Hence, cancer research is an important area to study, given societal health concerns. Moreover, studying the case of global cancer research provides more insights than restricting the study to one country. With global data we can more thoroughly examine the dynamic complexity of how successful product innovations are based on, and can be traced back to, cancer research. 
The objective of this paper is to explain successful product innovation success at the firm level, based upon collaboration with different partner types and firms' position in the global co-publication network for cancer research. Note that, in contrast to previous research, the paper uses a more specific proxy for product innovation in cancer, namely new molecular entities (NMEs) approved by the Food and Drug Administration (FDA), i.e. drugs that have not been marketed before.

Section 2 provides a literature overview, relative to the objective of this paper, and generates hypotheses. Section 3 explains the empirical strategy, data and research design. Section 4 describes the results of the econometrics and network analysis, relative to the hypotheses, while Section 5 provides conclusions and implications for later research.

\section{Literature}

\subsection{Relating knowledge, collaboration and innovation}

Studying the effects of the firm's networks on innovative output is, in the context of this paper, related to a specific theory of the firm. Literature on the theory of the firm recognizes that the generation of new, and the deployment of existing, knowledge is one of the principal sources of companies' competitive advantage (Grant 1996; Teece 2000). The underlying reasoning is that companies' knowledge bases translate into innovation activities that in turn allow for the development of new products, processes or services as well as the improvement of existing ones. Hence, the continuous generation of knowledge is one of the companies' most important objectives (Nonaka, Toyama, and Nagata 2000). Knowledge generation itself can be characterized by a largely cumulative step-by-step process in which new knowledge builds upon an existing foundation (Scotchmer 1991). However, the mere existence of knowledge does not imply that it is accessible and can be used by third parties (Mokyr 2002). Consequently, companies and other organizations need capabilities to effectively and efficiently search for, access, transfer, absorb and apply existing knowledge (Kogut and Zander 1992).

Therefore, the firm's capabilities to collaborate through networks matter because the recombination of existing knowledge is as an important source of novelty and innovation (Nelson and Winter 1982; Schumpeter 1939). Companies can use collaboration, in addition to their own investments, to further develop their knowledge base. Consistent with this, numerous studies indicate a positive relationship between $\mathrm{R} \& \mathrm{D}$ collaboration and companies' innovative performance in terms of patenting across countries and industries (Branstetter and Sakakibara 2002; Brouwer and Kleinknecht 1999; Czarnitzki, Ebersberger, and Fier 2007; Sampson 2007). In line with these results, Becker and Dietz (2004) find that $\mathrm{R} \& \mathrm{D}$ collaboration and the number of partners involved in the collaboration increase the probability of developing new products.

Literature regarding other industries suggests that collaboration with a diverse set of national and international partners, including suppliers, customers, competitors as well as universities and public research organizations, contributes to companies innovative performance (Duysters and Lokshin 2011; de Leeuw, Lokshin, and Duysters 2014). In the case of pharmaceuticals and medical care, discovering and implementing innovations requires a complex institutional arrangement, from research financing and collaborative development between partners to set up agreements on how to run clinical testing and 
apply for market approval (Windrum and García-Goñi 2008). Innovation, regulation and sales activities are complex in pharmaceuticals given the extensive involvement of public and private stakeholders (McMillan, Narin, and Deeds 2000; Murray 2002). These public and private stakeholders can range from pharmaceutical and biotechnology companies to universities and research institutes, insurance providers, medical care providers as well as NGOs or foundations which are engaged in cancer prevention, diagnosis and treatment, or the generation of new medical knowledge.

Therefore, the first hypothesis relates to having partners:

Hypothesis 1: The total number of collaboration partners in scientific publications is positively related to the development of new pharmaceuticals in the area of cancer.

However, the mere number of collaboration partners does not fully account for the quality and diversity of knowledge a company can access through its collaboration activities in order to support its innovative performance (Phelps 2010; Phelps, Heidl, and Wadhwa 2012). Therefore, one must turn to the specific types of collaboration and partners which characterize the intense collaboration activities the industry developed as a response to the rapidly developing, complex and widely dispersed knowledge base (Arora and Gambardella 1994; McKelvey 1996; Orsenigo, Pammolli, and Riccaboni 2001).

Biotechnology companies are an important type of partner. One reason why pharmaceutical and biotechnology firms collaborate is to make use of the complementarity of companies' key resources, knowledge bases and competencies as well as the opportunity to incorporate entrants' knowledge and competencies into incumbents' value chains (Arora and Gambardella 1994; Gambardella 1995; McKelvey 1996; Powell and Brantley 1992; Rothaermel 2000). Put differently, incumbent pharmaceutical firms have been interested in collaborating with biotechnology companies to gain access to, and experience with, new techniques that have created opportunities for the development of new pharmaceuticals (Malerba and Orsenigo 1996; McKelvey, Orsenigo, et al. 2004). In turn, collaboration enables biotechnology companies to access competencies and resources for the clinical development, approval and marketing of new drugs (Malerba and Orsenigo 1996; McKelvey, Rickne, et al. 2004). Empirical evidence on this phenomenon suggests that R\&D collaboration between incumbents and biotechnology companies as providers of new technologies is positively related to the number of new product developments by the incumbents (Rothaermel 2001). However, in subsequent research, several authors have stressed that the R\&D alliances between biotechnology and pharmaceutical companies have not lead to an increasing rate of drug discovery (Hopkins et al. 2007; Pisano 2006).

Thus, existing literature provides contradictory results, based on different empirical observations, of the effects of collaboration between biotechnology and pharmaceutical companies and the effects on innovative performance. We therefore propose a positive and a negative hypothesis.

Hypothesis 2a: The number of biotechnology collaboration partners in scientific publications is positively related to the development of new pharmaceuticals in the area of cancer.

Hypothesis 2b: The number of biotechnology collaboration partners in scientific publications is negatively related to the development of new pharmaceuticals in the area of cancer.

Universities and public research institutes are another important partner type in order to access more basic knowledge. Extensive research based on observations from different industries has identified advantages and disadvantages for the firm from this type of 
collaboration. Cassiman and Veugelers $(2002,1,179)$ find "firms that find the publicly available pool of knowledge more important for their innovation process [to be] more likely to benefit from cooperative agreements with other research institutes." The positive effect of R\&D collaboration on innovative performance has also been demonstrated in this context (Shan, Walker, and Kogut 1994). Collaboration between pharmaceutical firms and academic institutions is essential for successful innovative activities because the industry's $\mathrm{R} \& \mathrm{D}$ process is directly based on scientific knowledge (Cockburn and Henderson 1998). ${ }^{1}$

Empirical evidence suggests that collaboration between pharmaceutical companies and academic institutions through co-authorship of scientific papers, increases the number of patents granted in at least two of the three most important markets, i.e. the United States, Western Europe and Japan (Cockburn and Henderson 1998). Moreover, biotechnology companies collaborating with universities simultaneously have lower R\&D expenditures and higher innovative outputs in terms of patents, marketed products and products under development (George, Zahra, and Robley Wood 2002). ${ }^{2}$

The reasons why collaboration between firms and academic institutions in scientific publications may positively affect subsequent innovative performance are manifold (Faems, Van Looy, and Debackere 2005; Soh and Subramanian 2014). One has to do with access to complementary assets necessary to innovate, especially in a science-based industry; another is to stimulate the transfer of tacit as well as codified knowledge through collaboration; and a final is to spread the risks of R\&D among different partners.

Therefore, this part of the literature suggests a positive impact on innovation of collaboration between companies and academic institutions.

Hypothesis 3: The number of academic collaboration partners in scientific publications is positively related to the development of new pharmaceuticals in the disease area of cancer.

\subsection{Networks and innovative performance}

Moving beyond direct interactions with different types of partners, indirect ties and the position within the network may also influence the firm's product innovation. A key conceptualization underlying the literature on knowledge and innovation networks is that collaboration networks do not only provide access to the knowledge and experience of direct partners, but also to the knowledge and expertise of their partners' collaborators (Gulati and Gargiulo 1999). Beckman and Haunschild (2002) provide evidence that these indirect linkages supply companies with valuable and diverse information. Ahuja (2000) demonstrates the relevance of indirect linkages for firms' innovative activities, i.e. their number of patents. In line with our argument presented in Section 2.1, we propose that companies may benefit from indirect knowledge inflows from different types of organizations that they are connected with through their direct collaboration partners. Our hypotheses for indirect relations follow the above arguments for direct collaboration defined by type of partner:

Hypothesis 4: The total number of indirect collaboration partners in scientific publications is positively related to the development of new pharmaceuticals in the disease area of cancer.

${ }^{1}$ Small biotechnology companies are also dependent upon public science Feldman (2000).

'However, companies' financial performance is ultimately not superior to their counterparts without university linkages (George, Zahra, and Robley Wood 2002). 
Hypothesis 5a: The number of indirect biotechnology collaboration partners in scientific publications is positively related to the development of new pharmaceuticals in the disease area of cancer.

Hypothesis 5b: The number of indirect biotechnology collaboration partners in scientific publications is negatively related to the development of new pharmaceuticals in the disease area of cancer.

Hypotheses 6: The number of indirect academic collaboration partners in scientific publications is positively related to the development of new pharmaceuticals in the area of cancer

Indeed, network analysis is needed because the network may be the locus of innovation, due to opportunities to pool, exchange and develop new knowledge (Powell and Brantley 1992; Powell and Grodal 2005; Powell, Koput, and Smith-Doerr 1996) This notion relies on the assumption that knowledge is exchanged among the members of a collaboration network through formal and informal channels including collaborative work, technical and scientific advice as well as other forms of information exchange (Schrader 1991). These knowledge flows occur through the exchange of one's own and acquired knowledge among collaboration partners acting as both receiver and transmitter of knowledge (Gulati and Gargiulo 1999; Rogers and Kincaid 1981). Consequently, centrally located companies may have the largest opportunities to get access to more knowledge of greater fidelity (Hansen 2002; Monteiro, Arvidsson, and Birkinshaw 2008; Reagans and McEvily 2003).

Eigenvector centrality is a particularly useful concept in terms of potential knowledge exchange since it does not only take the connectivity of an individual company into account, but also the connectivity of its direct collaboration partners (Bonacich 1972, 1987, 2007). Companies with high eigenvector centrality scores should benefit from their position in the network since they get a higher amount and faster access to knowledge that is valuable for their own R\&D activities (Salman and Saives 2005).

Hagedoorn and Duysters (2002) find that eigenvector centrality based on technology alliances does not contribute to computer companies' technological performance in terms of patents. Using an extensive data-set on human biotechnology firms, Powell et al. (1999) find evidence that central network positions in terms of eigenvector centrality are positively related to a broad variety of performance measures, such as sales, employment growth, the number of patents and internally funded R\&D expenditures. In the context of US-based life science companies, Whittington, Owen-Smith, and Powell (2009) show that eigenvector centrality contributes to patent applications. Therefore:

Hypotheses 7: Companies' eigenvector centrality in a network of scientific publications is positively related to the development of new pharmaceuticals in the area of cancer.

Finally, another network measure is betweenness centrality, which incorporates the idea that interactions between non-neighboring actors within a network depend on other actors lying on a path between the two. Companies in this position may be seen as knowledge brokers which are participating actively in knowledge exchange within the network. By doing so, these companies get access to a diverse set of knowledge and thus support companies' innovative activities (Freeman 1979; Salman and Saives 2005).

In line with the latter arguments, Salman and Saives (2005) find a positive relationship between biotechnology companies' betweenness centrality in a network of strategic partnerships and their innovative performance. Regarding the biotechnology industry near Boston, Owen-Smith and Powell (2004) find that the relation between betweenness centrality and innovative activities can change as the network develops over time. More precisely, the 
authors find a negative relation between central network positions and successful patent applications in the early years of the network. It is important to note that as the network becomes more mature, centrality is positively associated with innovation. The changing importance of centrality is connected to the increasing importance of for-profit organizations, such as biotechnology companies and venture capitalists, in the local network (Owen-Smith and Powell 2004). Therefore:

Hypotheses 8: Companies' betweenness centrality in a network of scientific publications is positively related to the development of new pharmaceuticals in the disease area of cancer.

\section{Data, empirical strategy and research design}

\subsection{Data}

Our empirical analysis is based on a unique database for pharmaceutical cancer research, compiled from different sources. More precisely, we employ data on scientific publications, new drug approvals and the pharmaceutical companies found to be publishing in the field of cancer.

Data on publications provide a reasonably good, but partial indicator of collaborative knowledge production (Hoekman, Frenken, and van Oort 2009; Tijssen 2009). Here, it is used to build collaboration networks and to identify the different types of actors. To collect data on scientific co-publication, the BioPharmInsight database was used to compile a list of 30 medical indications in the therapeutic area of cancer. ${ }^{3}$ Each indication describes a medical condition or disease that allows for the development of a pharmaceutical therapy.

We used these medical indications in order to conduct a keyword search in the Web of Science databases (WoS), gathering data on scientific publications. In our data-set, we include all publications that contain at least one of the respective medical indications in their title. Further, we restrict the publication data to areas related to pharmaceutical research, i.e. those which have been assigned to the WoS categories "Biochemistry \& Molecular Biology," "Biotechnology \& Applied Microbiology," "Chemistry, Applied," "Chemistry, Medicinal," "Medicine, Research \& Experimental," "Pharmacology \& Pharmacy" or "Toxicology." Moreover, we exclude all publications that are not classified as journal articles to ensure that our data fulfill minimal criteria in quality and originality and also provides detailed information concerning the content and the origin of the publication.

To construct collaboration networks based on co-publications, we distinguish two sub-periods, 1998-2002 and 2004-2008. To create periods of equal length and to distinguish clearly between the two sub-periods, we do not use articles published in 2003. In total, the sample consists of 17,259 journal articles for which author affiliations have been reported in the WoS database. These affiliations are used to assign publications to the organizations from which they originated. More specifically, given the aims of this paper, we distinguish between academic institutions, i.e. universities, public research institutes and biotechnology companies as collaboration partners for the firms in our sample based on reported author affiliations. For companies, we checked manually whether their main line of business could

${ }^{3} \mathrm{http} / / /$ www.biopharminsight.com/index.html. A list of the respective medical indications can be found in Table A1 in the Appendix 1.

${ }^{4} \mathrm{~A}$ description of the categories can be found at http://ip-science.thomsonreuters.com/cgi-bin/jrnlst/jlsubcatg.cgi?PC=D. 
be described as traditional pharmaceuticals, biotechnology according to the biotechnology definition of the OECD (Organisation for Economic Co-operation and Development 2005) or whether the companies had another main line of business such as the production of chemicals, food or diagnostic devices.

Data on new molecular entities approved by the US Food and Drug Administration (FDA) are used as our proxy for successful product innovation. We obtained data on new pharmaceuticals in the disease area of cancer from the Drugs@FDA database. ${ }^{5}$ The database contains information on the trade name of new drugs, their generic names, the components providing pharmacological activity, the approval date and a classification of the newness of a drug formulation.

We match the medical indications with data on new molecular entities based on their pharmacological active ingredients. To match these elements, we follow Cerda (2007) in consulting the nineteenth edition of the Drug Information Handbook published by LexiComp and the American Pharmaceutical Association (Lacy et al. 2010). The handbook provides a list of the drugs' active ingredients, the medical indications the respective drug is used for and further information, such as adverse effects. Note that we consider only medical conditions that are listed on the FDA approved label. Hence, unlabeled and investigational uses are not considered.

Assigning publications and NMEs to the appropriate organization based on reported affiliations and applicants' names required several steps of standardization since the different types of raw data do not contain standardized organization names. We used publicly available information such as the organizations' websites, company reports, SEC filings as well as business information provided by Bloomberg as basis for the manual standardization of organization names. We account for changes in organizational boundaries, e.g. due to mergers and acquisitions, by assigning each institution to its highest order independent entity by 2008. We apply this strategy in order to take all collaboration and innovation activities into account, irrespective of the report of subsidiaries as author affiliations or as drug applicants. Specifically, all subsidiaries are assigned to the parent company if the latter holds more than 50 per cent of the shares. Following this rule, we also assign government agencies and laboratories to the responsible institution as well as research institutes to the corresponding umbrella organizations. ${ }^{6}$ As there is no clear distinction between university hospitals and medical departments, we therefore consider university hospitals as part of the university with which they are affiliated. ${ }^{7}$

We consulted different databases to obtain financial information for the 325 companies that published at least one scientific article from 1998 to 2002. The databases used did provide similar types of data about firms, but with different areas of coverage. The Amadeus database was used to obtain information on companies based in Europe. We supplement the data for firms headquartered outside Europe with data obtained from their financial reports provided by Company.info and the US Securities and Exchange Commission (SEC). Financial data are converted to US dollars using the exchange rate at the end of the respective year.

${ }^{5}$ http://www.fda.gov/Drugs/InformationOnDrugs/ucm135821.htm.

${ }^{6}$ This implies that different research institutes of the Max Planck Society are summarized as Max Planck Society.

${ }^{7}$ This implies that articles reporting, e.g. Dana-Farber Cancer Institute as affiliation, are assigned to Harvard University. The same applies to articles reporting Harvard Medical School as affiliation. 
The ReCap database is consulted to obtain data on firms' strategic R\&D alliances. ${ }^{8}$ The ReCap database contains information on alliances in the bio-pharmaceutical industry collected from various sources including press releases, SEC filings and company presentations. We restrict the ReCap data to alliances that focus on research and development activities in the field of cancer research.

\subsection{Empirical strategy to analyze collaboration and product innovation}

Our empirical strategy builds upon tools from social network research to analyze the relationship between firms' collaborative relations and their innovative success in pharmaceutical cancer research. Relations among organizations in networks are represented by co-publication links. The underlying assumption is that co-authors of a scientific publication have collaborated in its production. This assumes that they have engaged in the joint generation of new knowledge and in certain types of knowledge transfer that may facilitate innovative activities. Using the reported author affiliations, we distinguish collaborations according to different types of collaboration partners and build measures that account for the position of a particular firm within the co-publication network. These measures are included in the econometric analysis focusing on firms, their relations and positions within the co-publication network.

We use the number of new molecular entities approved by the FDA as a proxy for firms' innovative success with product innovations. Hence, the dependent variable determines the use of count data regression models with the Poisson model as the benchmark model for the empirical analysis. An important property of the Poisson regression framework is equidispersion, i.e. the variance is equal to the mean. We test this assumption using a regression-based test as proposed by Cameron and Trivedi (1990) and find significant overdispersion in all model specifications. Therefore, we use the negative binomial model with Huber-White robust standard errors for our econometric analysis. ${ }^{9}$

\subsection{Variables and descriptive statistics}

In our regression analysis, we concentrate on firms, their collaboration partners, network positions and new products. Table 1 provides an overview of the variables used in the analysis and their descriptive statistics.

We use the number of new molecular entities $\left(N M E_{04-08}\right)$ as the dependent variable (Cerda 2007; Grabowski and Wang 2006). This variable encompasses all new molecular entities, i.e. active ingredients which have never before been marketed in the US, and that were approved by the FDA from 2004 to 2008. During our period of observation 19 NMEs were approved in at least one of the 30 medical indications considered by this study. Thirteen of these NMEs could be assigned to 10 of the 139 companies included in our firm sample. This

\footnotetext{
${ }^{8} \mathrm{http}: / /$ www.recap.com/, a description of the database can be also found in Schilling (2009).

${ }^{9}$ Because the approval of new pharmaceuticals is rather rare event, the number of observed zeros might be higher than the count data models predict. Overdispersion might be the consequence of an excess number of zeros in the data. Negative binomial models take overdispersion and zero observations much better into account than the standard Poisson model. Moreover, in general it is not recommended to use zero-inflated models with small sample sizes and zero-inflated models do not necessarily lead to considerable improvements with respect to the goodness of fit criteria (Cameron and Trivedi 2009). The Vuong test is usually applied in the literature to test for zero-inflation. The required zero-inflated models did, however, not converge in our case.
} 


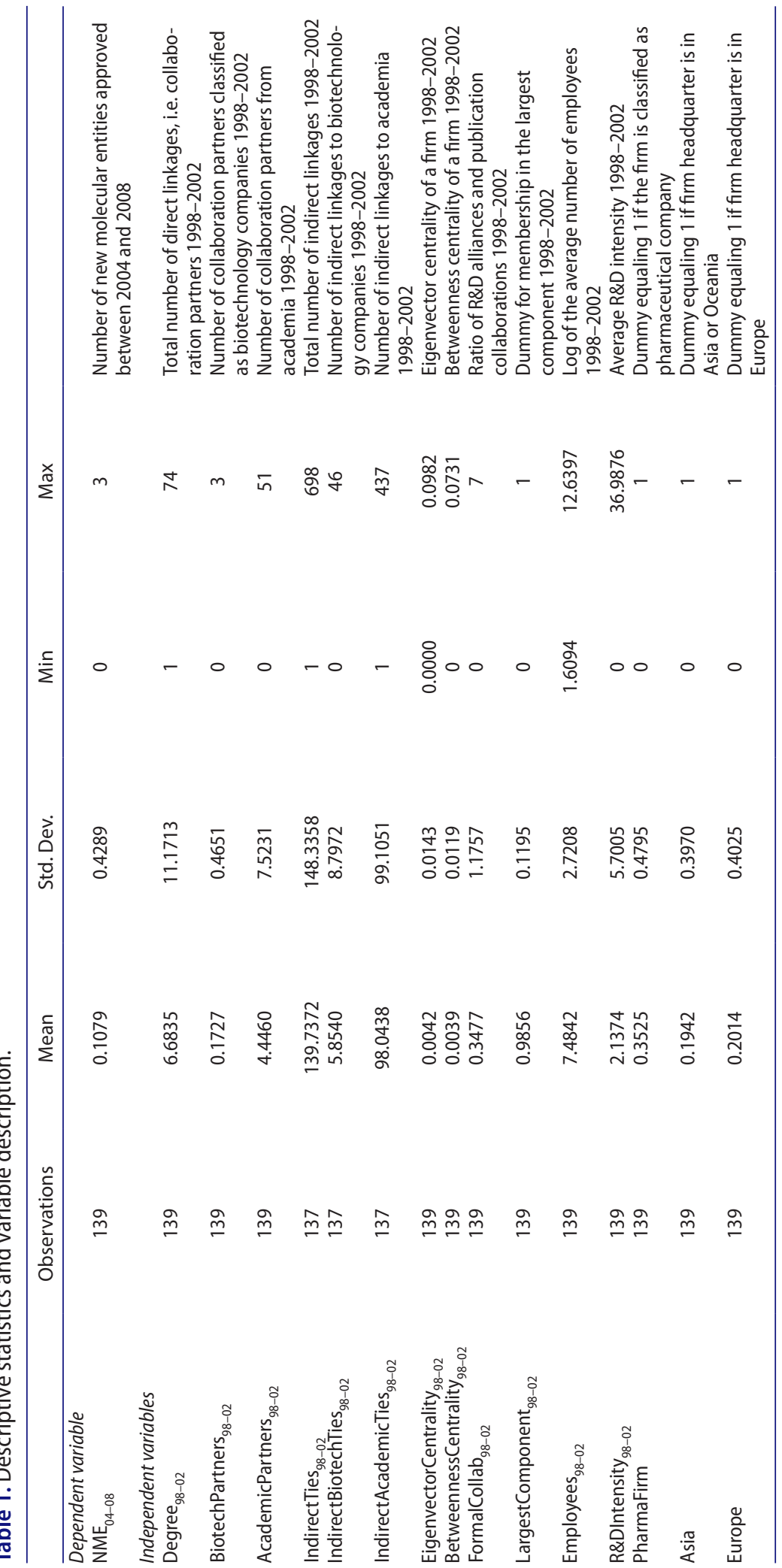

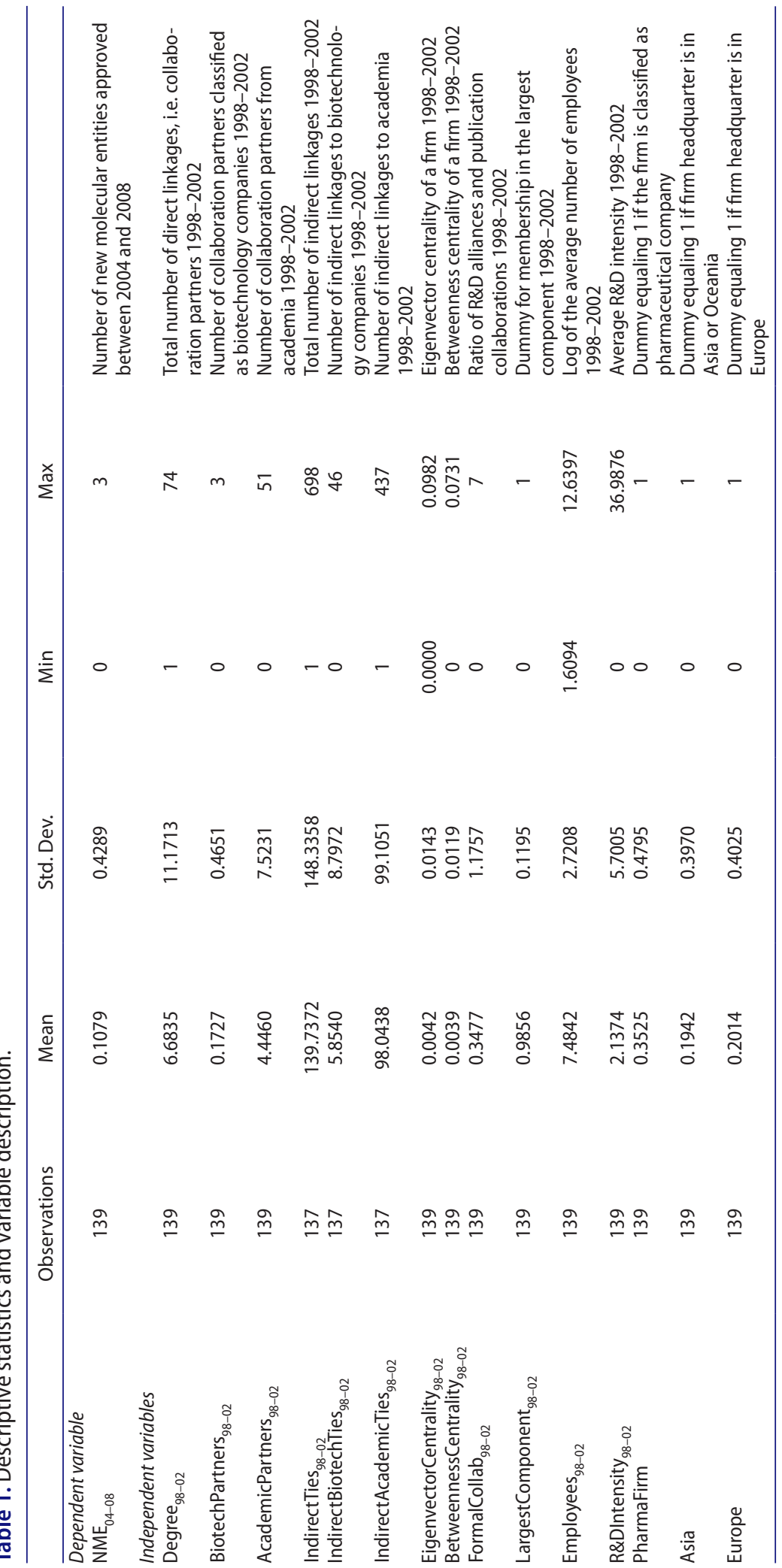

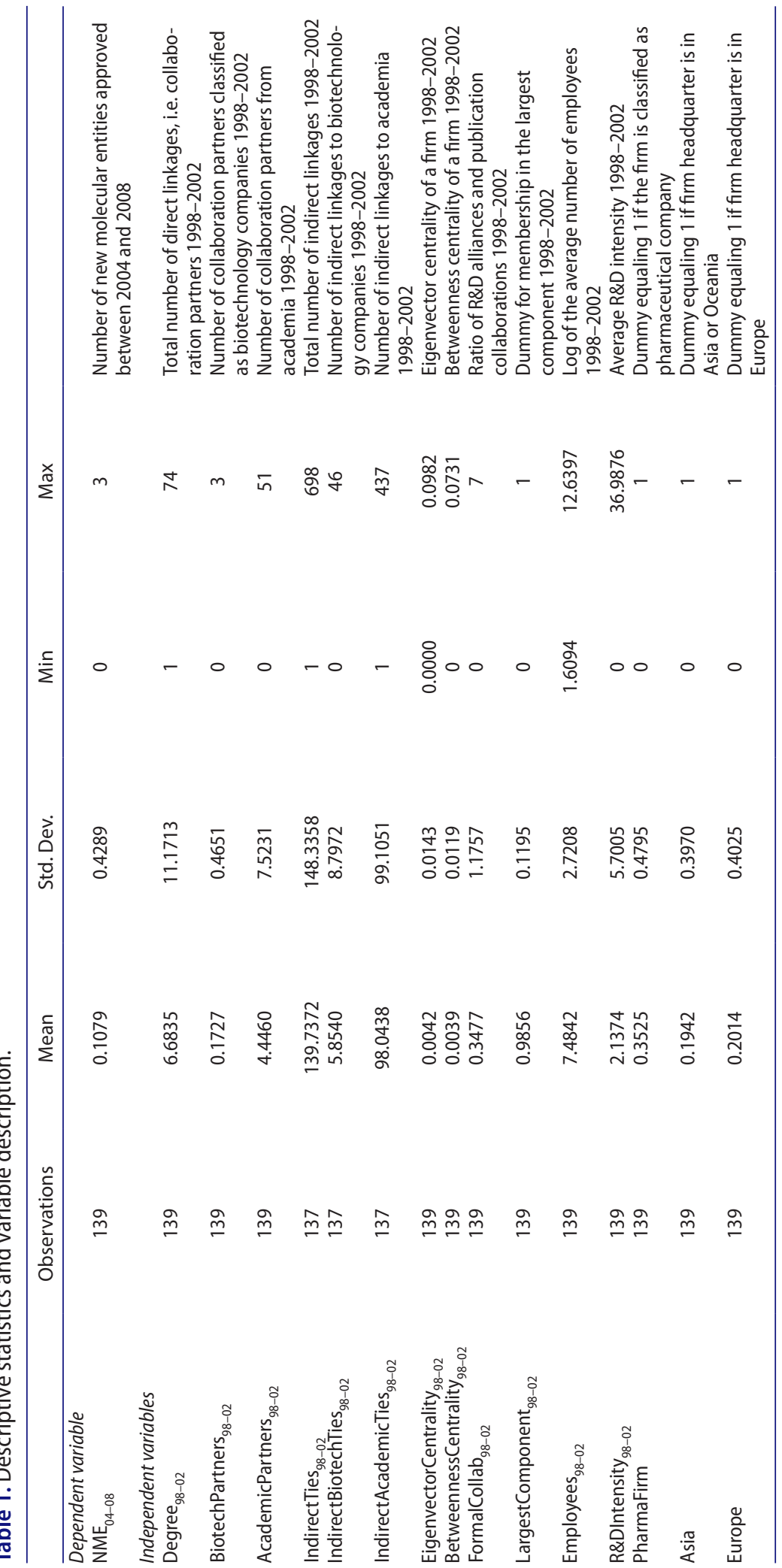

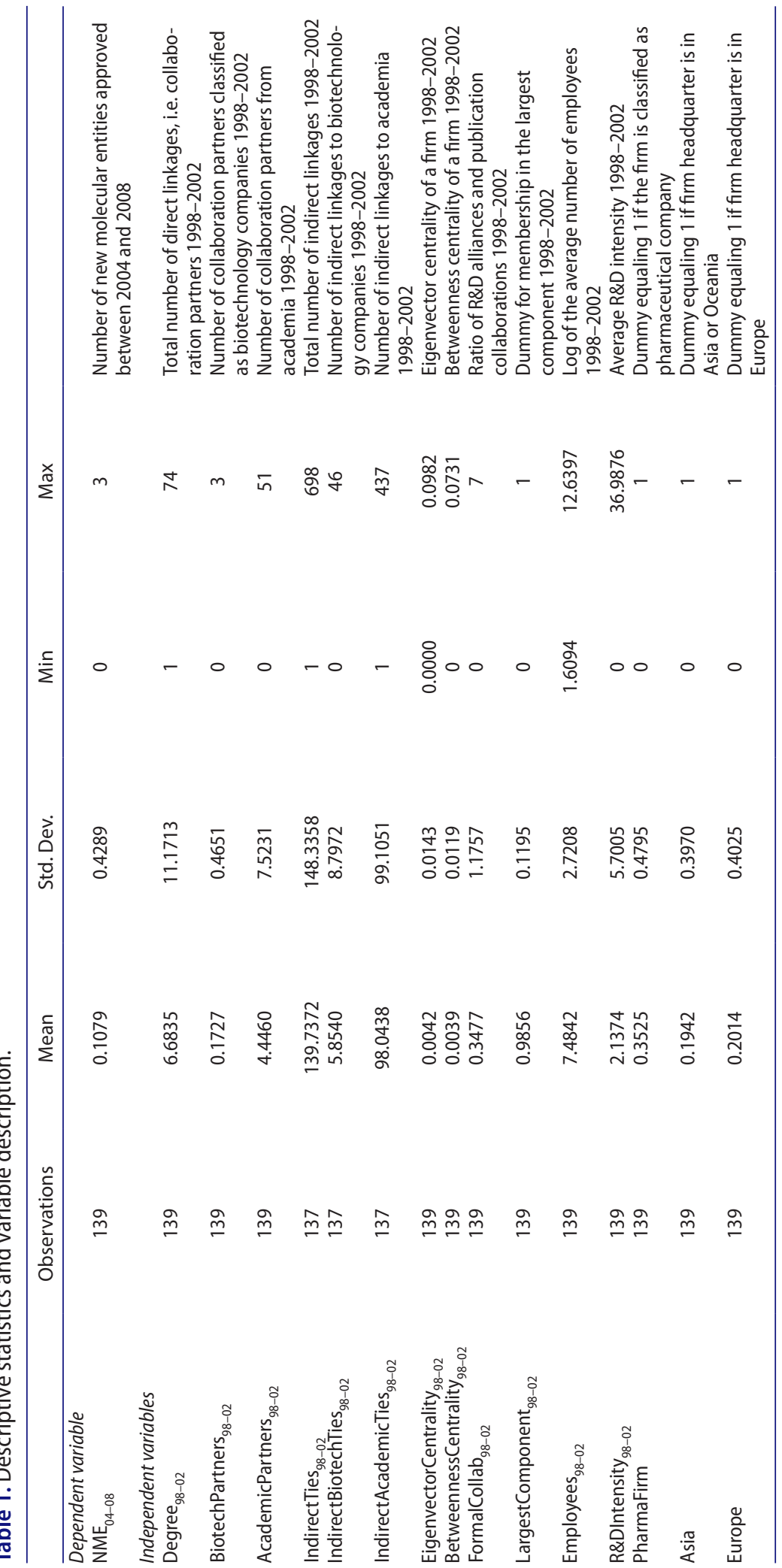

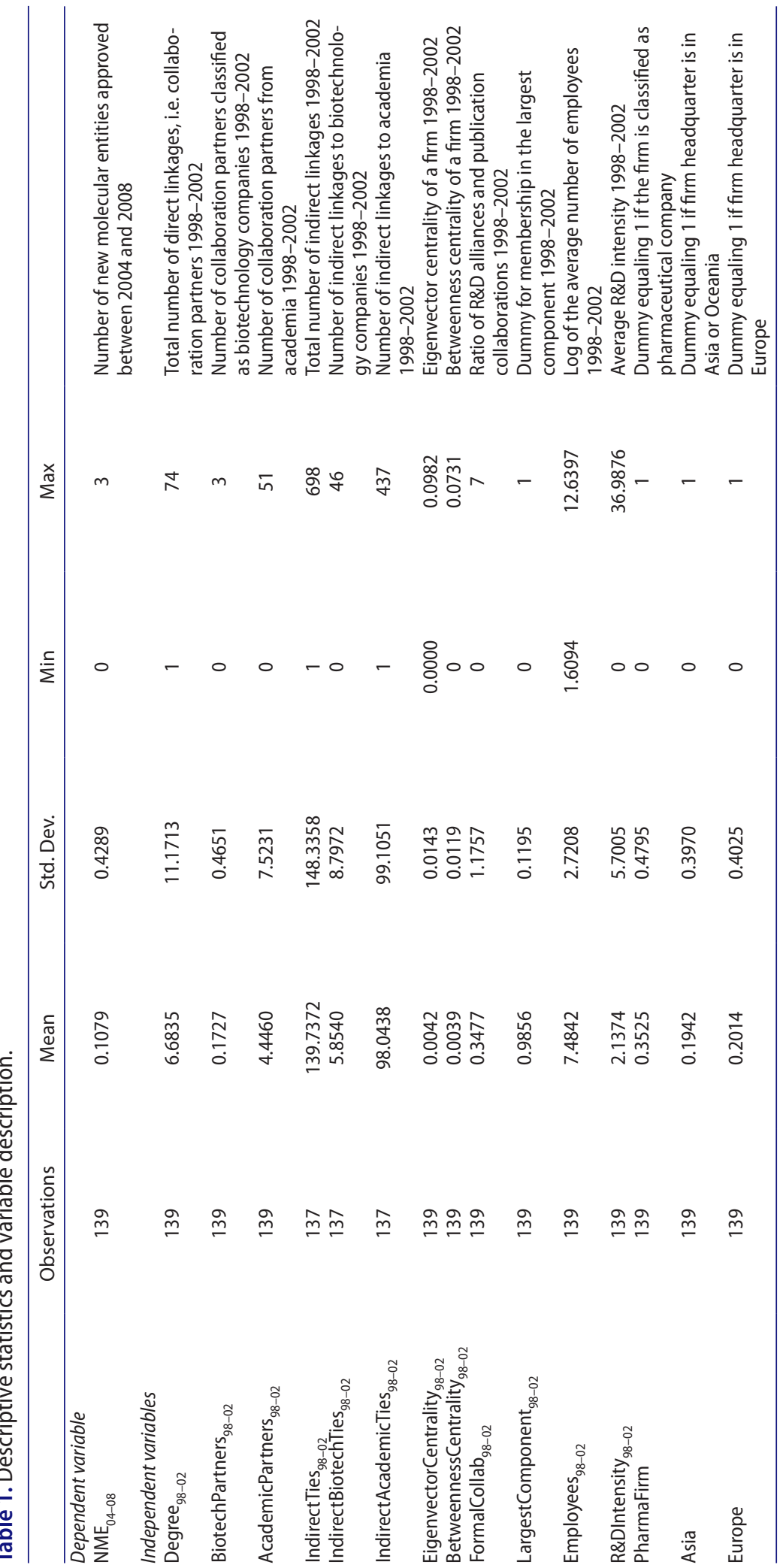


number may seem quite low, however, the total number of FDA approved new molecular entities has hardly exceeded 20 in recent years and even large pharmaceutical companies produce on average a rather low number of NMEs per year (Munos 2009). Pharmaceutical cancer research has been described as a field with rather low success rates (Kola and Landis 2004).

Accordingly, we count NMEs rather than patents. We count a NME as a single innovation although it might be used as a treatment for more than one type of cancer in order not to overstate the actual number of new products in the therapeutic area of cancer.

Our explanatory variables are constructed using social network analysis. To account for the number of collaboration partners, we calculate the number of different organizations a firm is linked to in the network during the years 1998-2002 through co-publications $\left(\right.$ Degree $\left._{98-02}\right)$. We further distinguish whether collaboration takes place with different partners from academia or different biotechnology companies because particularly these two types of organizations may provide access to knowledge relevant for the development of new pharmaceuticals (Cockburn and Henderson 1996, 1998; Rothaermel 2001). More precisely, we define AcademicPartner ${ }_{98-02}$ as the number of different academic partners, i.e. universities, research institutes and university hospitals, from 1998 to 2002. BiotechPartner ${ }_{98-02}$ represents the number of different collaboration partners during the period from 1998 to 2002 .

Additionally, we account for the total number of different organizations to which firms are indirectly linked during the years 1998-2002 (IndirectTies ${ }_{98-02}$ ). Specifically, we compute the number of organizations to which a firm is linked to at path length 2 . Hence, a firm is connected to these organizations through its direct collaboration partners. Similarly, we calculate the number of indirect ties to academia (IndirectAcademicTies ${ }_{98-02}$ ) and biotechnology companies (IndirectBiotechTies (I8-02 ).

In order to consider companies' connectivity of its direct collaboration partners, we calculate firms' eigenvector centralities defined as the sum of connections to other actors, weighted by their centrality scores (Bonacich 1972, 1987, 2007):

$$
\text { Eigenvector Centrality }_{i}=\frac{\sum_{j=1}^{N} c_{i, j} \text { Eigenvector Centrality }_{j}}{\lambda}
$$

This equation is solved using the eigenvectors and eigenvalues of the adjacency matrix (Bonacich 1972, 1987). $N$ refers to the total number of actors. $c_{i, j}$ is a binary indication of whether two actors $i$ and $j$ are connected. $\lambda$ denotes the largest eigenvalue of the adjacency matrix. Actors with high eigenvector centrality scores are connected to many other actors who are well connected.

Moreover, BetweennessCentrality ${ }_{98-02}$ accounts for the extent to which an actor can be regarded as a gatekeeper or broker in the network. Following Freeman (1977), we can express a standardized betweenness centrality index as follows:

$$
\text { Betwenness Centrality }_{i}=\frac{2 * \sum_{j<k} \frac{g_{j k}\left(a_{i}\right)}{g_{j k}}}{(N-1)(N-2)}
$$


with $i$ being distinct from $j$ and $k, g_{j k}\left(a_{i}\right)$ denotes the total number of the shortest paths linking actors $j$ and $k$ containing actor $i$. The probability that two actors, $j$ and $k$, are linked by a distinct actor $\mathrm{i}$ is provided by $g_{j k}\left(a_{i}\right) / g_{j k}$.

We account for two different strategies to access new knowledge by calculating the extent to which firms use one or the other. One strategy is for firms to engage in more informal modes of collaboration and encourage their employees to participate in research activities with internal and external colleagues. A second strategy is for firms to predominantly use more formal modes of collaboration like strategic alliances. More precisely, we divide the number of strategic R\&D alliances a company is engaged in by the number of collaborations in scientific publications (FormalCollab ${ }_{98-02}$ ).

LargestComponent $_{98-02}$ is a dummy equaling 1 if a firm is a member of the largest component, i.e. the largest connected part of the network, from 1998 to 2002 . The underlying assumption for using this variable is that knowledge is exchanged within the connected part of the network. Being part of the largest component should then influence the degree to which firms can profit from the ongoing knowledge exchange. Moreover, we account for firm size (Employees E8-02 ) using the log of the average number of employees from 1998 to 2002. R\&DIntensity ${ }_{98-02}$ accounts for the average R\&D intensity of a firm from 1998 to 2002. Following the Eurostat definition of $R \& D$ intensity ${ }^{10}$, we calculate this measure using firms' R\&D expenses divided by its operating revenues. The operating revenues of firms are used instead of sales accounts for the particularities of the industry since many of those companies do not generate revenues from selling products. But instead obtain licensing fees and (upfront) payments related to their R\&D activities. The dummy variable PharmaFirm equals one if a firm is active in the development or manufacturing of pharmaceuticals and its main activities do not fulfill the biotechnology definition of the OECD (2005). We add further dummies indicating whether a company's headquarter is located either in Asia or Oceania (Asia) or in Europe (Europe). ${ }^{11}$

As shown in Table A2 in the Appendix 1, many of our variables for partners and network positions of firms are rather highly correlated. The main reasons for the considerable correlation are that the variables are related through the underlying research network and that some variables are more specific subsets of others. Therefore, we introduce each collaboration variable separately in the regression models.

\section{Regression results}

\subsection{Partner types and innovative performance}

This section reports the findings of our econometric analysis referring to the hypotheses developed in the literature review as well as additional tests to be able to better interpret our results relative to the theory. Tables 2 and 3 present the results of the negative binomial regressions using the number of new molecular entities approved between 2004 and 2008 $\left(N M E_{04-08}\right)$ in the field of cancer as dependent variable. In contrast to Tables 2, Table 3 controls for the ratio of R\&D alliances and collaborations in publications (FormalCollab ${ }_{98-02}$ ).

In support of Hypothesis 1, we find a robust positive relationship between firms' total number of different collaboration partners $\left(\right.$ Degree $\left._{98-02}\right)$ and their innovative performance.

${ }^{10} \mathrm{http} / / /$ ec.europa.eu/eurostat/statistics-explained/index.php/Glossary:R_\%26_D_intensity.

${ }^{11}$ There are no companies headquartered in Africa or Latin America in our data-set. 


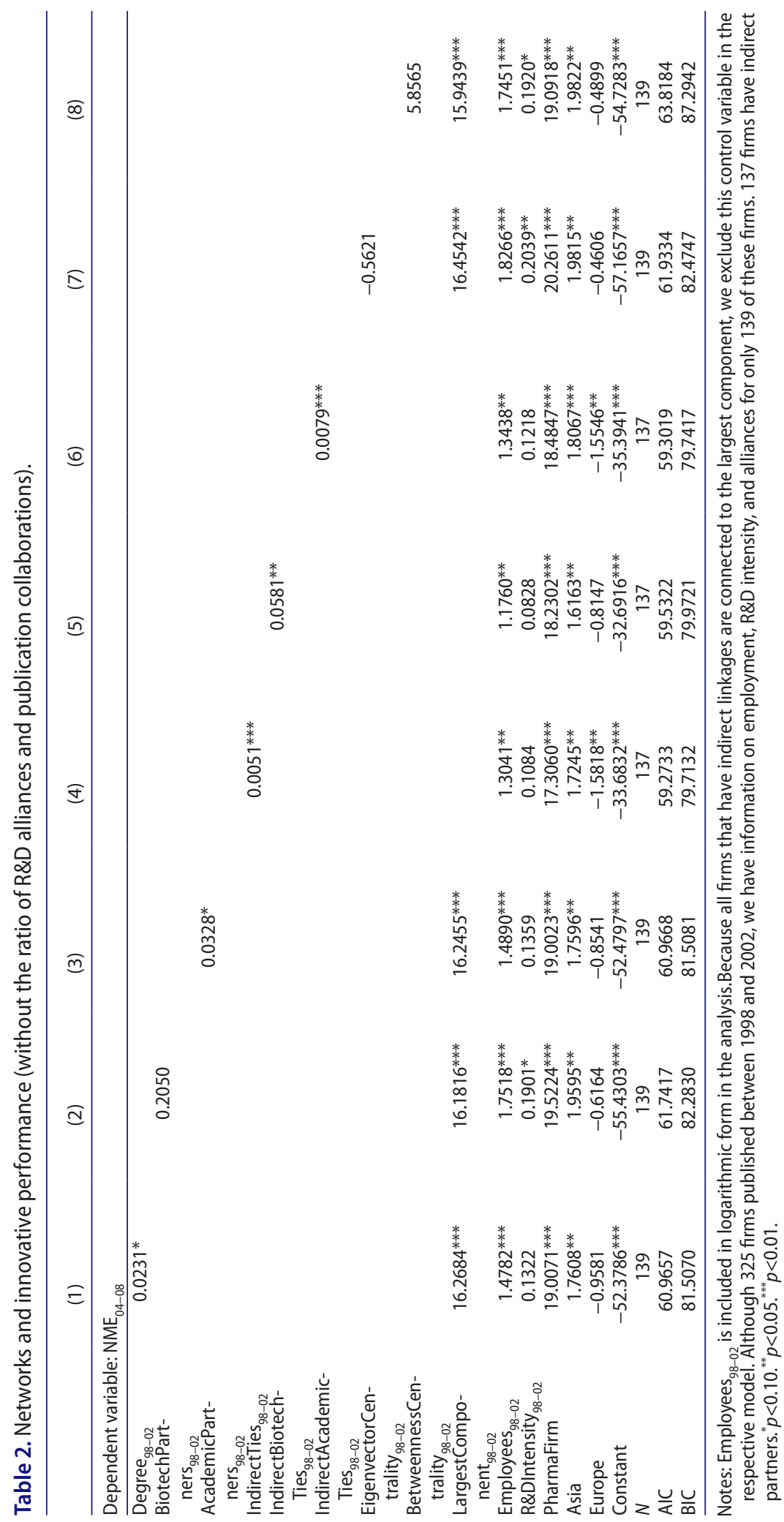




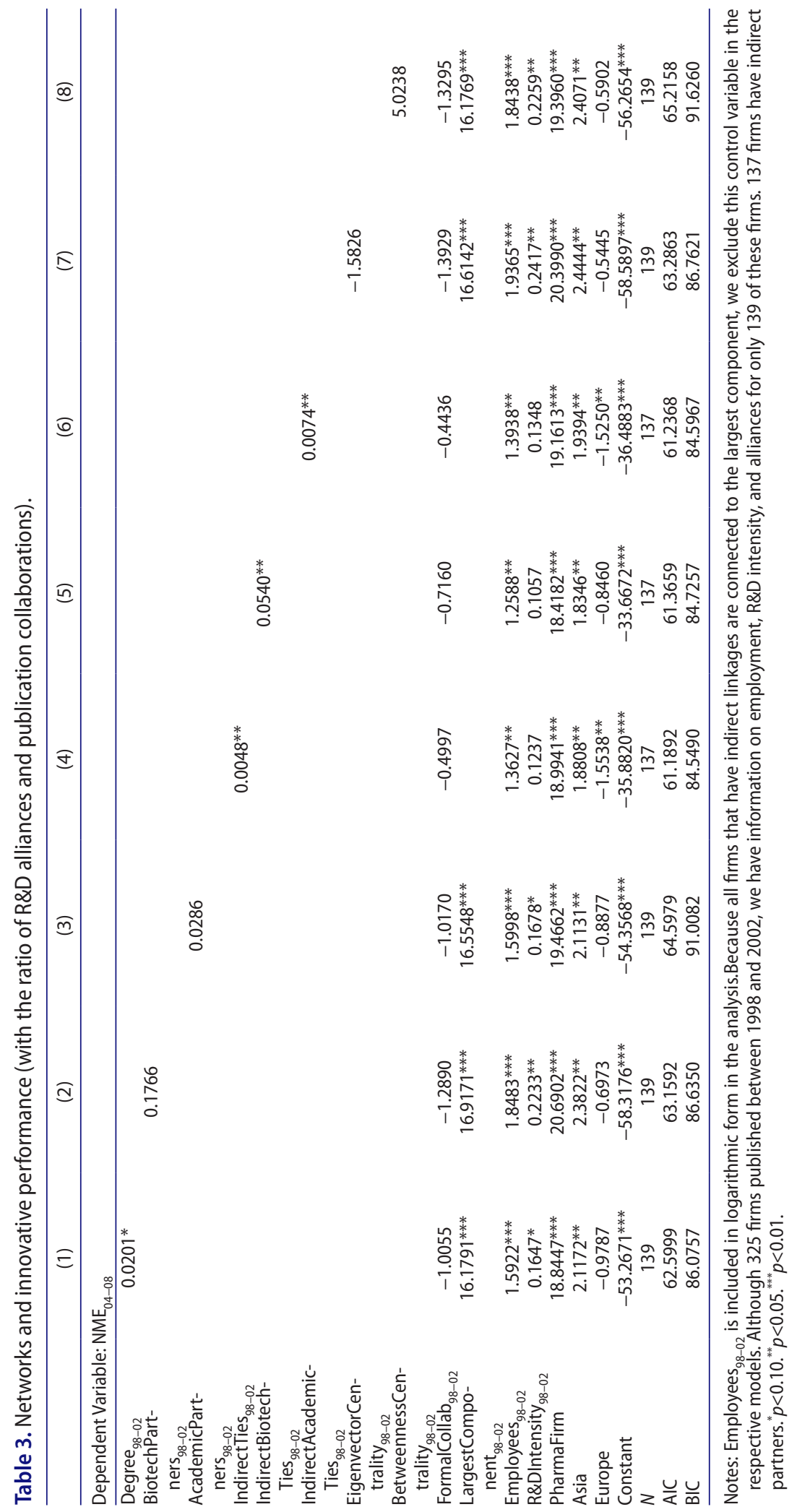


This result suggests that joint knowledge generation is needed with a diverse set of partner organizations. These collaborations provide access to knowledge, expertise, research materials and other resources to support the successful development of new pharmaceuticals.

Hypothesis 2 was presented as both a positive and negative hypothesis, due to mixed results in previous research about whether or not having biotechnology partners is positively associated with the innovative performance. Neither $\mathrm{H} 2 \mathrm{a}$ nor $\mathrm{H} 2 \mathrm{~b}$ could be supported. While other research emphasizes the importance of biotechnology for drug discovery and provision of research techniques, our results suggest that, at least for cancer, having a biotechnology partner is neither positively nor negatively linked to product innovation.

Hypothesis 3 suggests the benefits of collaborations with academic institutions (AcademicPartners ${ }_{98-02}$ ), and is supported in Model (3) in Table 2. Companies' innovative activities benefit from these collaborations, and our interpretation is that academic institutions provide access to relevant basic and clinical bio-medical knowledge that is not available to the firm in-house. Moreover, companies can increase their absorptive capacity through the joint generation and application of knowledge as indicated in co-publication projects with academic collaborators. They likely also benefit from their partners' scientific reputation. Nevertheless, we do not find evidence for a positive relationship between co-publication links to academic institutions and companies' innovative performance if we control for FormalCollab ${ }_{98-02}$ in Model (3) in Table 3. Our interpretation is that companies with numerous R\&D alliances have sufficient opportunities to access external knowledge which reduces the importance of joint knowledge generation with partners from academia.

Moreover, our results provide support for hypotheses 4, 5a and 6, thereby indicating the importance of indirect connections within the co-publication network. In particular, firms may benefit from indirect connections in general (IndirectTies ${ }_{98-02}$ ), indirect connections to biotechnology companies (IndirectBiotechTies ${ }_{98-02}$ ), and indirect connections to academia (IndirectAcademicTies ${ }_{98-02}$ ). Hence, indirect connections are important ways for companies to access knowledge of their partners' partners, and especially biotechnology companies and academic institutions. Our interpretation is that the firms can use indirect connections to access knowledge, which in turn can be incorporated into a firm's internal knowledge base in order to promote product innovation.

However, with respect to firms' network positions, we find neither evidence that firms can benefit from a high number of collaborations if their partners are highly connected (EigenvectorCentrality ${ }_{98-02}$ ) as proposed in Hypothesis 7 nor do they benefit from a gatekeeper position within the network (Betweenness Centrality ${ }_{98-02}$ ) as suggested in Hypothesis 8. This result is more puzzling, as it contradicts previous research in general and for this industry, as discussed in the final section.

Finally, a discussion of control variables follows. We find no significant relationship between the number of NMEs as a proxy for product innovation and the extent to which firms engage in scientific collaborations as opposed to strategic alliances (FormalCollab ${ }_{98-02}$ ). Membership in the largest component of the network (LargestComponent ${ }_{98-02}$ ) is positively and significantly related to product innovation, thereby supporting the argument that firms must be linked to the largest connected part of the network to benefit from the knowledge flows within it.

While larger firms (Employees ${ }_{98-02}$ ) generate a higher number of product innovations in the field of cancer, we do not find a robust (positive) relationship between firms' R\&D intensity (R\&DIntensity ${ }_{98-02}$ ) and product innovation. On the one hand, this finding might be 
driven by the measure for R\&D intensity, which captures companies overall R\&D expenses, instead of only those related to cancer. On the other hand, this result may suggest a need for a deeper understanding of underlying processes. It is also possible that in this science-based and $\mathrm{R} \& \mathrm{D}$ intense industry, $\mathrm{R} \& \mathrm{D}$ expenditures may not fully account for more informal modes of knowledge generation that we analyze with the variables for different types of collaboration partners.

We do find a positive and significant relation between PharmaFirm and the number of new molecular entities. This result suggests that product innovations in the field of cancer are dominated by pharmaceutical companies which have the required expertise in clinical research and drug approval. Firms headquartered in Asia show a higher number of product innovations in the field of cancer than their counterparts headquartered in North America; whereas, we find no robust relationship for companies headquartered in Europe.

\subsection{Robustness checks}

Empirical analyses of co-publication and other knowledge networks face the challenge of endogeneity due to omitted variables and reverse causality (Phelps, Heidl, and Wadhwa 2012). We address this issue in different ways.

Firstly, we use the total number of NMEs, i.e. the sum of NMEs in cancer and the number of NMEs in other disease areas, for the years from 1998 to 2002 as an additional control variable to mitigate the problem of omitted variables. The results suggest a rather robust positive relationship between the number of total lagged NMEs and the number of NMEs in the disease area of cancer. In accordance with our original findings, these results indicate a positive relationship between the number of indirect partners (IndirectTies ${ }_{98-02}$ ) as well as the number of indirect academic partners (AcademicPartners ${ }_{98-02}$ ) and the number of NMEs in cancer. In contrast to our original results, the coefficients for Degree ${ }_{98-02}$ and the number of indirect biotechnology partners (IndirectBiotechTies ${ }_{98-02}$ ) are not significantly related to successful new product development. These results are robust to the inclusion of the ratio of R\&D alliances and publication collaborations (FormalCollab ${ }_{98-02}$ ). Consequently, we find additional support for the importance of indirect partners in general, and especially for academic partners (but not for biotechnology partners) for the successful development of product innovations in terms of new cancer drugs.

Secondly, we investigate whether companies' innovative success affects their collaboration activities rather than vice versa. Building upon earlier work (e.g. Criscuolo, Salter, and Ter Wal 2014) based on the ideas of Granger (1969) we test whether the number of lagged NMEs $\left(N M E_{98-02}\right)$ in the disease area of cancer is significantly related to the number of companies' collaboration partners or their centrality scores. Controlling for the number of lagged collaboration partners and lagged centrality scores, the results do not suggest the presences of reverse causality with respect to the number of the different collaboration partners. However, we find a positive and significant relation between $N M E_{98-02}$ and the centrality scores. Consequently, we cannot rule out reverse causality for eigenvector and betweenness centrality. Since both measures are not significant in our original regressions, this finding does not invalidate the conclusion from our original analysis.

Our results, particularly for indirect partners, stay qualitatively the same if we restrict our results to firms that are part of the network's main component, to articles that are published in journals included in the WoS prior to 1998, and to journal articles published in journals 
classified as "basic research" according to the CHI classification of journals (Hamilton 2003). With the exception of the number of biotechnology companies a firm is indirectly connected to, we find no evidence of an inverted $\mathrm{u}$-shaped relationship between the number of direct or indirect collaboration partners and product innovation.

In addition, we conducted negative binomial regressions using the share of direct and indirect academic and biotechnology partners for the period 1998-2002 instead of their count as independent variables. The corresponding results are rather similar to the results of the original analysis. More precisely, we find a robust positive and significant relationship between the share of indirect biotechnology partners and the number of NMEs. In contrast to our original analysis which indicated a positive relationship between the number of indirect academic partners and the number of NMEs, we do not find a significant relationship between the share of indirect academic partners and the number of NMEs. One explanation for this finding can be that companies that have very few collaboration partners in the co-publication network may predominantly rely on collaborations with academic institution. Consequently, the relative importance of collaborators form academia is quite high despite the limited total number of academic partners and the limited potential to benefit from knowledge flows in the network.

\section{Conclusions}

In contrast to other industries, the biotechnology and pharmaceutical industry is highly dependent upon public science as well as collaboration with diverse partners in order to advance medical and technical understanding as well as to discover and test new pharmaceuticals. Therefore, the main reasons why companies in this industry must collaborate with different types of partners include the further development of companies' own knowledge base as well as the access to complementary knowledge in an environment of rapid scientific advances. Within this empirical context, this paper has focused upon untangling the influence of the firm's collaborative relations with different partner types and their network position on successful product innovation. In doing so, we focus on the development of new pharmaceuticals in the disease area of cancer. This disease area is an interesting area to study due to the spread of the disease, the large public investments into scientific research and the high degree of novelty in the product innovations required for treatment and diagnosis of the disease.

Our results suggest that direct and indirect co-publication links to diverse partners are beneficial for successful product innovation, as would be expected from existing literature. However, direct co-publication links with academic institutions and biotechnology companies do not unambiguously contribute to companies' innovative performance while indirect linkages do.

In accordance with Ahuja (2000), we find that direct and indirect linkages to diverse partners are beneficial for pharmaceutical product innovation in the disease area of cancer. This result suggests that companies should invest in establishing and maintaining linkages to a divers set of partners. In the more detailed analysis, our results indicate that not only direct collaboration with academic partners is beneficial for the successful development of new drugs. Moreover, companies seem to benefit from knowledge flows from academic institutions with which they are only indirectly connected. Firms need a wide range of direct and indirect linkages to academic institutions because such connections provide knowledge 
and expertise necessary to explore and to exploit scientific and technological opportunities, in a rapidly moving and expanding field.

Research suggests that collaboration, e.g. through strategic alliances, with biotechnology companies is an important translation mechanism of knowledge generated in academia into marketable products (Rothaermel 2001). In contrast, our results suggest that co-publication with biotechnology companies is a rather rare event. Moreover, we do not find a significant association with firms' innovative performance. One explanation for our finding is, as argued in existing literature, that biotechnology companies primarily serve as suppliers of research methods and promising compounds for new pharmaceuticals along the industry's knowledge supply chain (Nightingale and Mahdi 2006). As suppliers of methods and compounds they are only to a minor extent involved into collaborative research with pharmaceutical companies that leads to co-publications. An alternative explanation, which seems quite plausible, is that large pharmaceutical companies have developed biotechnology capabilities in-house, which implies that for this type of knowledge, they can develop ideas in-house or directly with academic institutions and therefore do not need to collaborate with biotechnology firms.

Moreover, we neither find evidence that firms can benefit from a gatekeeper nor a knowledge broker position within the network. They also do not benefit from a high connectedness of their collaboration partners. Our results thus contradict previous research suggesting a positive relation between eigenvector centrality and innovative performance (Powell et al. 1999) as well as between betweenness centrality and firms' innovative performance (Owen-Smith and Powell 2004). Our interpretation, which requires additional research to validate, is that the value of the network position per se for innovation has been overemphasized in previous research. At the same time, the importance of internal capabilities of the firm as well as the type of partners have been underemphasized. While companies need capabilities to effectively and efficiently use the knowledge they are confronted with in central network positions, the usefulness of this knowledge may depend on the diversity of connections within the network (Kogut and Zander 1992; Ter Wal et al. 2013).

Taken together, our interpretation of these results is that companies' main benefits in the co-publication network may not originate from joint knowledge generation through direct collaboration with organizations of different types. Instead, companies' drug development activities primarily benefit from knowledge that originates from direct partners' collaboration partners. With respect to economic theory, this interpretation suggests a need for reconsidering the ways of how knowledge is generated and transferred in co-publication projects and their importance for product innovation, particularly in science-based industries. Moreover, these results suggest refining our understanding of the circumstances under which direct or indirect connections via co-publications network are beneficial for product innovations.

An interesting issue for further research is whether and how networks help to mitigate the problem of declining productivity in $\mathrm{R} \& \mathrm{D}$ in the pharmaceutical industry. Our results strongly suggest that biotechnology companies are not core partners for the large pharmaceutical firms-at least not in cancer and not when one links co-publication networks to product innovations. Therefore, future research on the relationship between biotechnology 
firms and large pharmaceutical firms should focus on whether partnering with biotechnology firms does in fact provide knowledge and techniques that help to stimulate in an indirect manner product innovations in large pharmaceutical companies.

Also, given that our results differ in important ways from previous research, our recommendation is that later research follows dimensions of our research design, which differs from much of previous research, in order to examine whether our results are robust across different industries or disease areas in pharmaceuticals. More precisely, we recommend three improvements to research design: (1) Examine co-publications of scientific articles, rather than the commonly used databases of collaborative agreements in general, if the foci are on the generation and development of knowledge. (2) Employ a better proxy for product innovation such as NME rather than the commonly used one of patents. In comparison with NMEs, patents do not fully capture the idea of product innovation in a specific disease area. This is because, in this industry patent applications are usually filed shortly after the discovery of a new compound. At this time its therapeutic potential as well as its use against a particular indication is not yet fully examined and its successful market approval cannot be foreseen. ${ }^{12}$ (3) Limit an analysis to a specific disease area, rather than examining the whole industry, because this gives a more precise measurement and understanding of particular knowledge and innovation processes.

\section{Acknowledgments}

This research was partly conducted while Bastian Rake was at the Graduate College "The Economics of Innovative Change" at the Friedrich Schiller University Jena. An earlier version was disseminated under the title "Research Network Position and Innovative Performance: Evidence from the Pharmaceutical Industry." We are grateful to the German Research Foundation (DFG) for financial support through grant number DFG-GK-1,411. We acknowledge the Sten A Olsson Foundation, in supporting the research program lead by Professor McKelvey and entitled "Radical Innovation for the Enhancement of the Swedish Economy." We thank Matthew J. Higgins for sharing the ReCap data with us. We thank Uwe Cantner, Pablo D'Este, Holger Graf, Ivan Savin, the participants of the Brown Bag Seminar at the Graduate College "The Economics of Innovative Change" in March 2012, the participants of the Brown Bag Seminar at the University of Passau in June 2012, the participants of the 14th ISS Conference 2012 in Brisbane, Australia and the participants of the Workshop on Innovation in Health Care on December 12, 2013 in Oslo, Norway for useful comments, expressed interest and concerns. The usual caveats apply.

\section{Disclosure statement}

No potential conflict of interest was reported by the authors.

\section{ORCID}

Maureen McKelvey (iD http://orcid.org/0000-0002-1457-7922

Bastian Rake (D) http://orcid.org/0000-0002-9116-9789

${ }^{12}$ Alternative measures for companies' innovative success include companies' revenues with particular drugs in the field of cancer research. However, this type of information is not easily to obtain and was not available to us. 


\section{References}

Ahuja, G. 2000. "Collaboration Networks, Structural Holes, and Innovation: A Longitudinal Study." Administrative Science Quarterly 45 (3): 425-455.

Arora, A., and A. Gambardella. 1994. "The Changing Technology of Technological Change: General and Abstract Knowledge and the Division of Innovative Labour." Research Policy 23 (5): 523-532.

Becker, W., and J. Dietz. 2004. "R\&D Cooperation and Innovation Activities of Firms - Evidence for the German Manufacturing Industry." Research Policy 33 (2): 209-223.

Beckman, C. M., and P. R. Haunschild. 2002. "Network Learning: The Effects of Partners' Heterogeneity of Experience on Corporate Acquisitions." Administrative Science Quarterly 47 (1): 92-124.

Bonacich, P. 1972. "Factoring and Weighting Approaches to Status Scores and Clique Identification." The Journal of Mathematical Sociology 2 (1): 113-120.

Bonacich, P. 1987. "Power and Centrality: A Family of Measures." American Journal of Sociology 92 (5): $1170-1182$.

Bonacich, P. 2007. "Some Unique Properties of Eigenvector Centrality." Social Networks 29 (4): $555-564$.

Branstetter, L. G., and M. Sakakibara. 2002. "When Do Research Consortia Work Well and Why? Evidence from Japanese Panel Data." The American Economic Review 92 (1): 143-159.

Brouwer, E., and A. Kleinknecht. 1999. "Innovative Output, and a Firm's Propensity to Patent: An Exploration of 5CIS6 Micro Data." Research Policy 28 (6): 615-624.

Cameron, A. C., and P. K. Trivedi. 1990. "Regression-based Tests for Overdispersion in the Poisson Model.” Journal of Econometrics 46 (3): 347-364.

Cameron, A. C., and P. K. Trivedi. 2009. Microeconometrics Using Stata. College Station: Stata Press.

Cassiman, B., and R. Veugelers. 2002. "R\&D Cooperation and Spillovers: Some Empirical Evidence from Belgium." The American Economic Review 92 (4): 1169-1184.

Cerda, R. A. 2007. "Endogenous Innovations in the Pharmaceutical Industry." Journal of Evolutionary Economics 17 (4): 473-515.

Cockburn, I. M., and R. M. Henderson. 1996. "Public-private Interaction in Pharmaceutical Research." Proceedings of the National Academy of Sciences 93 (23): 12725-12730.

Cockburn, I. M., and R. M. Henderson. 1998. "Absorptive Capacity, Co-authoring Behavior, and the Organization of Research in Drug Discovery." The Journal of Industrial Economics 46 (2): 157-182.

Criscuolo, P., A. Salter, and Anne L. J. Ter Wal. 2014. "Going Underground: Bootlegging and Individual Innovative Performance." Organization Science 25 (5): 1287-1305.

Czarnitzki, D., B. Ebersberger, and A. Fier. 2007. "The Relationship between R\&D Collaboration, Subsidies and R\&D Performance: Empirical Evidence from Finland and Germany." Journal of Applied Econometrics 22 (7): 1347-1366.

Duysters, G., and B. Lokshin. 2011. "Determinants of Alliance Portfolio Complexity and Its Effect on Innovative Performance of Companies." Journal of Product Innovation Management 28 (4): 570-585.

Faems, D., B. Van Looy, and K. Debackere. 2005. “Interorganizational Collaboration and Innovation: Toward a Portfolio Approach." Journal of Product Innovation Management 22 (3): 238-250.

Feldman, M. P. 2000. "Where Science Comes to Life: University Bioscience, Commercial Spin-offs, and Regional Economic Development." Journal of Comparative Policy Analysis 2 (3): 345-361.

Freeman, L. C. 1977. "A Set of Measures of Centrality Based on Betweenness." Sociometry 40 (1): $35-41$.

Freeman, L. C. 1979. "Centrality in Social Networks Conceptual Clarification." Social Networks 1 (3): 215-239.

Gambardella, A. 1995. Science and Innovation: The US Pharmaceutical Industry during the 1980s. Cambridge: Cambridge University Press.

George, G., S. A. Zahra, and D. Robley Wood Jr. 2002. "The Effects of Business-University Alliances on Innovative Output and Financial Performance: A Study of Publicly Traded Biotechnology Companies." Journal of Business Venturing 17 (6): 577-609. 
Grabowski, H. G., and Y. R. Wang. 2006. "The Quantity and Quality of Worldwide New Drug Introductions, 1982-2003." Health Affairs 25 (2): 452-460.

Granger, C. W. J. 1969. "Investigating Causal Relations by Econometric Models and Cross-spectral Methods." Econometrica 37 (3): 424-438.

Grant, R. M. 1996. “Toward a Knowledge-based Theory of the Firm.” Strategic Management Journal 17 (S2): 109-122.

Gulati, R., and M. Gargiulo. 1999. “Where Do Interorganizational Networks Come from?” American Journal of Sociology 104 (5): 1439-1493.

Hagedoorn, J., and G. Duysters. 2002. "Learning in Dynamic Inter-firm Networks: The Efficacy of Multiple Contacts." Organization Studies 23 (4): 525-548.

Hamilton, K. S. 2003. Subfield and Level Classification of Journals CHI No. 2012-R. Haddon Heights, NJ: CHI Research Inc.

Hansen, M. T. 2002. "Knowledge Networks: Explaining Effective Knowledge Sharing in Multiunit Companies." Organization Science 13 (3): 232-248.

Hoekman, J., K. Frenken, and F. van Oort. 2009. "The Geography of Collaborative Knowledge Production in Europe.” The Annals of Regional Science 43 (3): 721-738.

Hopkins, M. M., P. A. Martin, P. Nightingale, A. Kraft, and S. Mahdi. 2007. “The Myth of the Biotech Revolution: An Assessment of Technological, Clinical and Organisational Change." Research Policy 36 (4): 566-589.

International Agency for Research on Cancer. 2014. World Cancer Report 2014. Geneva: WHO Press. Kogut, B., W. Shan, and G. Walker. 1992. "The Make or Cooperate Decision in the Context of an Industry Network." In Networks and Organizations: Structure, Form and Action, edited by N. Nohria and R. Eccles, 348-365. Boston, MA: Harvard Business School Press.

Kogut, B., and U. Zander. 1992. "Knowledge of the Firm, Combinative Capabilities, and the Replication of Technology." Organization Science 3 (3): 383-397.

Kola, I., and J. Landis. 2004. "Can the Pharmaceutical Industry Reduce Attrition Rates?" Nature Reviews Drug Discovery 3 (8): 711-716.

Lacy, C. F., L. L. Armstrong, M. P. Goldman, and L. L. Lance, eds. 2010. Drug Information Handbook, 19th ed. Hudson: Lexi-Comp.

de Leeuw, T., B. Lokshin, and G. Duysters. 2014. "Returns to Alliance Portfolio Diversity: The Relative Effects of Partner Diversity on Firm's Innovative Performance and Productivity." Journal of Business Research 67 (9): 1839-1849.

Malerba, F., and L. Orsenigo. 1996. "The Dynamics and Evolution of Industries." Industrial and Corporate Change 5 (1): 51-87.

McKelvey, M. 1996. Evolutionary Innovations: The Business of Biotechnology. Oxford: Oxford University Press.

McKelvey, M., L. Orsenigo, and F. Pammolli. 2004. "Pharmaceuticals Analyzed through the Lens of a Sectoral Innovation System.” In Sectoral Systems of Innovation: Concepts, Issues and Analyses of Six Major Sectors in Europe, edited by F. Malerba, 73-120. Cambridge: Cambridge University Press.

McKelvey, M., A. Rickne, and J. Laage-Hellman. 2004. The Economic Dynamics of Modern Biotechnology. Cheltenham: Edward Elgar.

McMillan, G. S., F. Narin, and D. L. Deeds. 2000. "An Analysis of the Critical Role of Public Science in Innovation: The Case of Biotechnology." Research Policy 29 (1): 1-8.

Mokyr, J. 2002. The Gifts of Athena: Historical Origins of the Knowledge Economy. Princeton: Princeton University Press.

Monteiro, L. F., N. Arvidsson, and J. Birkinshaw. 2008. "Knowledge Flows within Multinational Corporations: Explaining Subsidiary Isolation and Its Performance Implications." Organization Science 19 (1): 90-107.

Munos, B. 2009. "Lessons from 60 Years of Pharmaceutical Innovation." Nature Reviews Drug Discovery 8 (12): 959-968.

Murray, F. 2002. "Innovation as Co-evolution of Scientific and Technological Networks: Exploring Tissue Engineering." Research Policy 31 (8-9): 1389-1403. 
Nelson, R. R., and S. G. Winter. 1982. An Evolutionary Theory of Economic Change. Cambridge: The Belkap Press.

Nightingale, P., and S. Mahdi. 2006. "The Evolution of Pharmaceutical Innovation." In Knowledge Accumulation and Industry Evolution: The Case of Pharma-Biotech, edited by M. Mazzucato and G. Dosi, 73-111. Cambridge: Cambridge University Press.

Nonaka, I., R. Toyama, and A. Nagata. 2000. "A Firm as a Knowledge-creating Entity: A New Perspective on the Theory of the Firm." Industrial and Corporate Change 9 (1): 1-20.

Nooteboom, B. 1999. Inter-firm Alliances: Analysis and Design. London: Routledge.

Nooteboom, B. 2009. A Cognitive Theory of the Firm: Learning, Governance and Dynamic Capabilities. Cheltenham: Edward Elgar.

Organisation for Economic Co-operation and Development. 2005. Statistical Definition of Biotechnology, Paris.

Orsenigo, L., F. Pammolli, and M. Riccaboni. 2001. “Technological Change and Network Dynamics: Lessons from the Pharmaceutical Industry." Research Policy 30 (3): 485-508.

Owen-Smith, J., and W. W. Powell. 2004. "Knowledge Networks as Channels and Conduits: The Effects of Spillovers in the Boston Biotechnology Community." Organization Science 15 (1): 5-21.

Owen-Smith, J., M. Riccaboni, F. Pammolli, and W. W. Powell. 2002. "A Comparison of U.S. and European University-industry Relations in the Life Sciences." Management Science 48 (1): 24-43.

Phelps, C., R. Heidl, and A. Wadhwa. 2012. "Knowledge, Networks, and Knowledge Networks: A Review and Research Agenda." Journal of Management 38 (4): 1115-1166.

Phelps, C. C. 2010. "A Longitudinal Study of the Influence of Alliance Network Structure and Composition on Firm Exploratory Innovation." Academy of Management Journal 53 (4): 890-913.

Pisano, G. P. 2006. "Can Science Be a Business? Lessons from Biotech." Harvard Business Review 84 (10): 114-125.

Powell, W., and P. Brantley. 1992. "Competitive Cooperation in Biotechnology: Learning through Networks?” In Networks and Organizations, edited by R. Eccles and N. Nohria, 366-394. Boston, MA: Harvard Business School Press.

Powell, W., and S. Grodal. 2005. "Networks of Innovators." In The Oxford Handbook of Innovation, edited by J. Fagerberg, D. Mowery, and R. Nelson, 56-85. Oxford: Oxford University Press.

Powell, W., K. Koput, and L. Smith-Doerr. 1996. "Interorganizational Collaboration and the Locus of Innovation: Networks of Learning in Biotechnology." Administrative Science Quarterly 41 (1): 116-145.

Powell, W., K. Koput, L. Smith-Doerr, and J. Owen-Smith. 1999. "Network Position and Firm Performance: Organizational Returns to Collaboration in the Biotechnology Industry." In Research in the Sociology of Organizations, edited by S. Andrews and D. Knoke, 129-159. Greenwich: JAI Press.

Powell, W. W., D. R. White, K. W. Koput, and J. Owen-Smith. 2005. "Network Dynamics and Field Evolution: The Growth of Interorganizational Collaboration in the Life Sciences." American Journal of Sociology 110 (4): 1132-1205.

Rafols, I., M. M. Hopkins, J. Hoekman, J. Siepel, A. O’Hare, A. Perianes-Rodríguez, and P. Nightingale. 2014. "Big Pharma, Little Science?: A Bibliometric Perspective on Big Pharma's R\&D Decline." Technological Forecasting and Social Change 81: 22-38.

Reagans, R., and B. McEvily. 2003. "Network Structure and Knowledge Transfer: The Effects of Cohesion and Range." Administrative Science Quarterly 48 (2): 240-267.

Rogers, E. M., and D. L. Kincaid. 1981. Communication Networks: Toward a New Paradigm for Research. New York: Free Press.

Roijakkers, N., and J. Hagedoorn. 2006. "Inter-firm R\&D Partnering in Pharmaceutical Biotechnology since 1975: Trends, Patterns, and Networks.” Research Policy 35 (3): 431-446.

Rothaermel, F. T. 2000. “Technological Discontinuities and the Nature of Competition.” Technology Analysis \& Strategic Management 12 (2): 149-160. 
Rothaermel, F. T. 2001. “Complementary Assets, Strategic Alliances, and the Incumbent's Advantage: An Empirical Study of Industry and Firm Effects in the Biopharmaceutical Industry." Research Policy 30 (8): 1235-1251.

Salman, N., and A.-L. Saives. 2005. "Indirect Networks: An Intangible Resource for Biotechnology Innovation." R\&D Management 35 (2): 203-215.

Sampson, R. C. 2007. "R\&D Alliances and Firm Performance: The Impact of Technological Diversity and Alliance Organization on Innovation.” The Academy of Management Journal 50 (2): 364-386.

Schilling, M. A. 2009. "Understanding the Alliance Data." Strategic Management Journal 30 (3): 233-260.

Schrader, S. 1991. "Informal Technology Transfer between Firms: Cooperation through Information Trading." Research Policy 20 (2): 153-170.

Schumpeter, J. A. 1939. Business Cycles. New Yorn: McGraw-Hill.

Scotchmer, S. 1991. "Standing on the Shoulders of Giants: Cumulative Research and the Patent Law." The Journal of Economic Perspectives 5 (1): 29-41.

Shan, W., Gordon Walker, and B. Kogut. 1994. "Interfirm Cooperation and Startup Innovation in the Biotechnology Industry." Strategic Management Journal 15 (5): 387-394.

Soh, P.-H., and A. M. Subramanian. 2014. "When Do Firms Benefit from University-Industryn R\&D Collaborations? The Implications of Firm R\&D Focus on Scientific Research and Technological Recombination.” Journal of Business Venturing 29 (6): 807-821.

Teece, D. J. 2000. "Strategies for Managing Knowledge Assets: The Role of Firm Structure and Industrial Context." Long Range Planning 33 (1): 35-54.

Ter Wal, A., O. Alexy, J. Block, and P. Sandner. 2013. "The Best of Both Worlds: The Benefits of Specialized-brokered and Diverse-closed Syndication Networks for New Venture Success." Paper Presented at the 35th DRUID Celebration Conference Barcelona, Spain.

Tijssen, R. J. 2009. "Measuring the Corporate Web of Science: Research and Partnership Networks within the European Pharmaceutical Industry." In Innovation Networks in Industries, edited by F. Malerba and N. S. Vonortas, 81-104. Cheltenham: Edward Elgar.

Whittington, K. B., J. Owen-Smith, and W. W. Powell. 2009. "Networks, Propinquity, and Innovation in Knowledge-intensive Industries.” Administrative Science Quarterly 54 (1): 90-122.

Windrum, P., and M. García-Goñi. 2008. "A Neo-schumpeterian Model of Health Services Innovation." Research Policy 37 (4): 649-672.

\section{Appendix 1}

Table A1. List of Medical Indications

\begin{tabular}{ll}
\hline Angiogenesis & Liver Cancer \\
Bladder Cancer & Lung Cancer \\
Bone Cancer & Lymphoma \\
Brain Cancer & Melanoma \\
Breast Cancer & Metastasis \\
Cervical Cancer & Mouth or Throat Cancer \\
Chemotherapy related & Mucositis \\
Colon Cancer & Multiple myeloma \\
Endometrial Cancer & Non-Hodgkin Lymphoma \\
Gastrointestinal Cancer & Ovarian Cancer \\
Head and Neck Cancer & Pancreatic Cancer \\
Hematological Cancer & Prostate Cancer \\
Kaposi Sarcoma & Radiation Related \\
Kidney Cancer & Soft-Tissue Sarcoma \\
Leukemia & Solid Tumors \\
\hline
\end{tabular}


Table A2. Correlations

\begin{tabular}{|c|c|c|c|c|c|c|}
\hline & $(1)$ & $(2)$ & (3) & (4) & (5) & (6) \\
\hline $\begin{array}{l}\text { (1) Degree } \\
\text { (2) AcademicPartners } \\
\text { (3) BiotechPartners } \\
\text { (4) IndirectTies } \\
{ }_{98-02} \\
\text { (5) IndirectAcademicTies } \\
\text { (6) IndirectBiotechTies } \\
{ }_{98-02} \\
\text { (7) BetweennessCentrality } \\
\text { (8) EigenvectorCentrality } \\
\text { (9) FormalCollab } \\
\text { (10)-02 } \\
\text { (10) LargestComponent } \\
\text { (11) Employees } \\
\text { (12) R\&DIntensity } \\
\text { (13) PharmaFirm } \\
\text { (14) Asia } \\
\text { (15) Europe }\end{array}$ & $\begin{array}{l}1.0000 \\
0.9435^{* * * *} \\
0.5405^{* * *} \\
0.8423^{* * * *} \\
0.8179^{* * *} \\
0.7730^{* * *} \\
0.5865^{* * *} \\
0.7948^{* * *} \\
-0.1405 \\
0.0617 \\
0.4432^{* * *} \\
-0.1454 \\
0.3565^{* * *} \\
-0.1363 \\
0.2850^{* * *} \\
\end{array}$ & $\begin{array}{l}1.0000 \\
0.3630^{* * *} \\
0.8446^{* * *} \\
0.8105^{* * *} \\
0.8285^{* * *} \\
0.5780^{* * *} \\
0.8188^{* * *} \\
-0.1290 \\
0.0555 \\
0.4164^{* * *} \\
-0.1229 \\
0.3719^{* * *} \\
-0.0874 \\
0.2932^{* * *} \\
\end{array}$ & $\begin{array}{l}1.0000 \\
0.4190^{* * *} \\
0.4229^{* * *} \\
0.2723^{* *} \\
0.2760^{* *} \\
0.2951^{* * *} \\
-0.1085 \\
0.0450 \\
0.3336^{* * *} \\
-0.1101 \\
0.1800^{*} \\
-0.1044 \\
0.1612 \\
\end{array}$ & $\begin{array}{l}1.0000 \\
0.9965^{* * *} \\
0.9135^{* * *} \\
0.6315^{* * *} \\
0.6755^{* * *} \\
-0.1413 \\
0.0000 \\
0.4029^{* * *} \\
-0.1228 \\
0.3405^{* * *} \\
-0.0980 \\
0.1840^{*} \\
\end{array}$ & $\begin{array}{l}1.0000 \\
0.8990^{* * *} \\
0.6263^{* * *} \\
0.6488^{* * *} \\
-0.1432 \\
0.0000 \\
0.3953^{* * *} \\
-0.1259 \\
0.3334^{* * *} \\
-0.1163 \\
0.1741^{*} \\
\end{array}$ & $\begin{array}{l}1.0000 \\
0.6628^{* * *} \\
0.6488^{* * *} \\
-0.0941 \\
0.0000 \\
0.3368^{* * *} \\
-0.0795 \\
0.2618^{* *} \\
-0.1512 \\
0.1551 \\
\end{array}$ \\
\hline (15) Europe & $(7)$ & (8) & (9) & $(10)$ & $(11)$ & $(12)$ \\
\hline $\begin{array}{l}\text { (7) BetweennessCentrality } \\
\text { (8) EigenvectorCentrality } \\
\text { (98-02 } \\
\text { (9) FormalCollab } \\
\text { (10) } \text { LargestComponent }_{98-02} \\
\text { (11) Employees } \\
\text { (12) R\&DIntensity } 02 \\
\text { (13) PharmaFirm } \\
\text { (14) Asia } \\
\text { (15) Europe }\end{array}$ & $\begin{array}{l}1.0000 \\
0.2396^{* *} \\
-0.0779 \\
0.0393 \\
0.2582^{* *} \\
-0.0934 \\
0.2677^{* *} \\
-0.1392 \\
0.2338^{* *} \\
\end{array}$ & $\begin{array}{l}1.0000 \\
-0.0873 \\
0.0361 \\
0.3165^{* * *} \\
-0.0961 \\
0.1903^{*} \\
-0.1297 \\
0.1600\end{array}$ & $\begin{array}{l}1.0000 \\
-0.3251^{* * *} \\
-0.2588^{* *} \\
0.2426^{* *} \\
-0.1596 \\
-0.1009 \\
-0.1396\end{array}$ & $\begin{array}{l}1.0000 \\
0.0116 \\
0.0319 \\
-0.0373 \\
-0.0934 \\
0.0607\end{array}$ & $\begin{array}{l}1.0000 \\
-0.4316^{* * *} \\
0.2345^{* *} \\
0.2797^{* * *} \\
0.2051^{*}\end{array}$ & $\begin{array}{l}1.0000 \\
-0.0252 \\
-0.1788^{*} \\
-0.1392\end{array}$ \\
\hline (15) Europe & $(13)$ & (14) & (15) & & & \\
\hline $\begin{array}{l}\text { (13) PharmaFirm } \\
\text { (14) Asia } \\
\text { (15) Europe }\end{array}$ & $\begin{array}{l}1.0000 \\
0.0564 \\
0.1550\end{array}$ & $\begin{array}{l}1.0000 \\
-0.2466^{* *}\end{array}$ & 1.0000 & & & \\
\hline
\end{tabular}

${ }^{*} p<0.05,{ }^{, * *} p<0.01,{ }^{* * * *} p<0.001$. 